\title{
As contribuições de um projeto \\ de extensão na formação inicial do professor de Matemática
}

\author{
Marnei Luis Mandler \\ marnei.mandler@udesc.br \\ Regina Helena Munhoz \\ rmunhoz@gmail.com
}

Eliane Bihuna de Azevedo

eliane.bihuna@gmail.com

\author{
Graciela Moro \\ gracimoro@gmail.com
}

Professores e pesquisadores da Universidade do Estado de Santa Catarina, Brasil.
Integración de la docencia y la extensión /

Intervenciones

RECEPCIÓN: 24/06/16

ACEPTACIÓN FINAL: 03/10/16

\section{Resumo}

Este texto apresenta as contribuições proporcionadas por um projeto de extensão universitária junto ao processo formativo de uma futura professora de Matemática. Trata-se de um projeto em andamento, desenvolvido por pesquisadores brasileiros da Universidade do Estado de Santa Catarina (UDESC), no âmbito de um Programa de Extensão intitulado "Ensino de Ciências e Matemática: abordagens interdisciplinares". Por meio da intervenção proporcionada por um Clube de Matemática, a professora em formação é responsável por abordar conteúdos curriculares de Matemática junto a alunos do Ensino Básico, sua futura área de atuação profissional. Acreditamos que, ao proporcionar o contato semanal com o ambiente escolar, explorando conceitos matemáticos de forma lúdica e com o apoio de materiais didáticos variados, a extensão universitária contribui para a integração entre universidade e escola, colaborando para a formação docente com um olhar voltado à prática profissional e diretamente relacionado com atividades de ensino e de pesquisa.

\section{Palavras-chave}

- Clube de Matemática

- Formação Inicial do Professor de Matemática

- Atividades Lúdicas para o Ensino de Matemática

- Indissociabilidade entre Pesquisa, Ensino e Extensão

\section{Resumen}

Este artículo presenta contribuciones producidas por un proyecto de extensión universitaria en conjunto con el proceso de formación de un futuro profesor de Matemáticas. Este es un proyecto aún en curso, desarrollado por investigadores brasileños en la Universidade do Estado de Santa Catarina (UDESC), en el ámbito de un programa de extensión titulado "Ensino de Ciências e Matemática: abordagens interdisciplinares". El maestro en formación es responsable por tratar contenidos de matemáticas con los estudiantes de educación básica, su futura área profesional, en un Club de Matemática. Se cree que al proporcionar el contacto semanal con el ambiente escolar, la exploración de conceptos matemáticos a través del juego y con apoyo de una variedad de materiales, la extensión universitaria contribuye a la integración entre universidad y escuela y a la formación del profesorado con la mirada en la práctica profesional y directamente relacionada con las actividades de enseñanza e investigación.

\section{Palabras-clave}

- Club de Matemáticas

- Formación inicial del profesor de Matemáticas

- Actividades lúdicas para la enseñanza de la matemática

- Inseparabilidad de investigación, enseñanza y extensión

\section{Para citación de este artículo}

Mandler, M. L.; Munhoz, R. H.; Bihuna de Azevedo, E. y Moro, G. (2016). As contribuições de um projeto de extensão na formação inicial do professor de matemática. En Revista +E versión digital, (6), pp. 330-335. Santa Fe, Argentina: Ediciones UNL 


\author{
as contribuições no campo da extensão \\ são os mais visíveis, visto que o projeto \\ permite considerar a matemática \\ mais atrativa para esses estudantes
}

\section{Introdução}

Neste texto apresentamos algumas contribuições que a prática proporcionada pelo desenvolvimento de atividades de um projeto de Extensão Universitária, na área de Educação e Cultura, pode propiciar à formação inicial de discentes de Licenciatura em Matemática.

Mais especificamente, abordamos algumas das consequências no processo formativo de uma acadêmica de Licenciatura em Matemática pela Universidade do Estado de Santa Catarina (UDESC) em função de sua participação como bolsista de um Programa de Extensão responsável, dentre outras ações, por desenvolver um Clube de Matemática junto a uma Escola Pública da rede municipal de Joinville, Santa Catarina, Brasil.

Nesse Clube, implantado no início do ano letivo de 2015, os conteúdos curriculares de matemática são abordados por meio de atividades lúdicas, em encontros semanais realizados no contra turno letivo dos alunos participantes. O público alvo do Clube é formado por estudantes das séries finais da primeira etapa do nível de escolarização brasileiro chamado de Ensino Fundamental, atendendo alunos que cursam o sexto, sétimo ou oitavo ano desse nível de ensino.

Idealizado a partir de uma demanda trazida à Universidade por intermédio da coordenação pedagógica da própria escola contemplada, o Clube "Um por todos e todos pela Matemática" (como nomeado posteriormente pelos próprios alunos) nasceu de um projeto piloto de extensão, intitulado Clube de Matemática na Escola, proposto em 2014 e colocado em prática a partir de março de 2015 por uma equipe de professores do curso de Licenciatura em Matemática da UDESC, inseridos no Grupo de Pesquisa em Educação Matemática e Sistemas Aplicados ao Ensino (Grupo PEMSA).

Em função dos bons resultados obtidos no primeiro ano de atividades e pelo interesse da escola pública em manter os laços com a Universidade, no ano letivo de 2016 o projeto Clube de Matemática continua sendo oferecido, agora como uma das ações inseridas em um Programa de Extensão intitulado "Ensino de Ciências e Matemática: abordagens interdisciplinares". A equipe desse programa também cresceu, passando a ser constituída por docentes e discentes do Programa de Pós-Graduação em Ensino de Ciências, Matemática e Tecnologias da UDESC e professores das Licenciaturas em Física, Química e Matemática, além de discentes (professores em formação inicial) desses três cursos.

\section{O Programa "Ensino de Ciências e Matemática: abordagens interdisciplinares"}

A partir da aplicação de projetos isolados de extensão, como o "Clube de Matemática na Escola", foi sentida a necessidade de integração entre as ações extensionistas desenvolvidas por docentes dos cursos de Licenciatura em Matemática, Licenciatura em Física e Licenciatura em Química da UDESC.

Nessa perspectiva e com o propósito de possibilitar um maior acesso dos estudantes e professores da Educação Básica atuantes na região de Joinville (cidade localizada na região sul do Brasil) às novas ferramentas educacionais e novas visões epistemológicas e didáticas a respeito do processo educacional, um grupo de docentes do Ensino Superior da UDESC criou o Programa de Extensão "Ensino de Ciências e Matemática: abordagens interdisciplinares", que está em sua primeira edição no ano de 2016.

O propósito deste Programa consiste em desenvolver práticas pedagógicas interdisciplinares a partir da construção de eixos temáticos que norteiam o trabalho pedagógico nos seus aspectos teóricos e práticos, articulando os diferentes saberes e linguagens a partir do trabalho colaborativo entre professores e acadêmicos das Licenciaturas da UDESC.

Por meio do oferecimento de ações didático-pedagógicas diferenciadas, este Programa visa a uma institucionalização de espaços de formação inicial e continuada para professores de Física, Química e Matemática, ao mesmo tempo em que busca 
indicar caminhos adequados e capazes de colaborar com a formação crítica, criativa e cidadã dos alunos da Educação Básica, de modo com que tais sujeitos, oriundos de diferentes segmentos sociais, possam conviver em espaços plurais e que emanam conhecimentos, competências e atitudes constantemente atualizados e articulados em termos de teoria e prática.

Neste contexto, o Programa é composto por três ações de extensão. A primeira ação intitulada "Clube de Matemática na Escola" é desenvolvida junto a alunos do ciclo básico por meio de atividades que buscam explorar a matemática de forma mais atrativa, fora dos padrões tradicionais com que costuma ser tratada em sala de aula, utilizando para isso recursos pedagógicos variados, como jogos didáticos, artefatos lúdicos, desafios matemáticos, exercícios de pensamento lateral e lógica (Azevedo, Moro, Viana, Mandler, Munhoz e Dunzer, 2016).

A segunda ação do programa, nomeada "Materiais didáticopedagógicos para o ensino de Química" possui como proposta incentivar a utilização de materiais didáticos pelos professores, apontando para a necessidade de uma prática interdisciplinar e para a valorização de materiais alternativos, com foco na confecção de materiais didáticos ou paradidáticos, kits de experimentos, simulações, jogos, equipamentos e audiovisuais, dentre outros artefatos que podem auxiliar no ensino de Química para o nível básico. Por sua vez, a proposta da terceira ação, intitulada "Formação Continuada: Interdisciplinaridade em Foco" consiste no oferecimento de cursos de capacitação continuada para os professores da Educação Básica, envolvendo temáticas como o Programa Nacional do Livro Didático (PNLD) e "A construção do conceito de número pela criança na Educação Infantil". Nesse texto, nos restringimos a destacar os impactos da ação "Clube de Matemática na Escola" na formação inicial de uma acadêmica do curso de Licenciatura em Matemática, que participa ha dois anos consecutivos como bolsista desse projeto de extensão, atuando como responsável pelo planejamento e execução das atividades do Clube, sob a orientação de alguns professores da área de Matemática e Educação Matemática. Tal restrição ocorre devido ao fato de que este projeto conta com apenas esta bolsista e tem apresentado resultados bem positivos tanto para a sua formação inicial quanto em relação ao aprendizado em matemática dos alunos da Educação Básica participantes do Clube.

\section{O papel da extensão universitária na formação do futuro professor de Matemática}

De acordo com o Projeto Político Pedagógico ${ }^{1}$ (PPC) do curso de Licenciatura em Matemática da UDESC, o licenciado em Matemática deve receber, em sua formação inicial, condições que Ihe permitam atuar em seu campo profissional por meio de: - Conhecimentos sólidos referentes aos conteúdos de matemática do Ensino Fundamental e Médio;

- Conhecimentos de matemática superior que Ihe possibilitem aprofundar os conhecimentos dos programas curriculares do Ensino Fundamental e Médio e destacar a importância dos conteúdos a ser ensinados enquanto professor, a partir de abordagens interdisciplinares;

- Conhecimentos didáticos e pedagógicos que Ihe propiciem o exercício de sua atividade docente, embasado nos conhecimentos de história, psicologia e filosofia das ciências e da matemática;

- Habilidade para discutir, analisar e avaliar propostas curriculares, livros didáticos e materiais pedagógicos;

- Capacidade de elaborar e desenvolver projetos de ensino e pesquisa que contribuam para a sua prática docente, considerando os aspectos regionais específicos de seu campo de atuação.

Nesse contexto, destacamos que os objetivos da formação inicial do professor de Matemática consistem em possibilitar reflexões sobre o papel do professor nos processos de ensino e aprendizagem, com domínio de conteúdos específicos e de metodologias para o ensino de Matemática e uma visão interdisciplinar que o permita contextualizar seus diferentes saberes, relacionando a matemática com a vida cotidiana e com outras áreas, a partir de uma postura crítica, criativa e dotado da visão humanística necessária para sua atuação docente.

Porém, quais ações constantes do percurso formativo do futuro professor de Matemática devem ser direcionadas para a sua prática docente, de forma a lhe oferecer meios de exercitar os conhecimentos construídos no âmbito acadêmico junto ao seu futuro campo de atuação profissional?

De acordo com as Diretrizes Curriculares Nacionais para a Formação Inicial em Nível Superior (em cursos de licenciatura, cursos de formação pedagógica para graduados e cursos de 
segunda licenciatura) e para a formação continuada (Brasil, 2015), os cursos de formação de profissionais do magistério da Educação Básica devem adotar, dentre seus princípios:

"a articulação entre a teoria e a prática no processo de formação docente, fundada no domínio dos conhecimentos científicos e didáticos, contemplando a indissociabilidade entre ensino, pesquisa e extensão; o reconhecimento das instituições de educação básica como espaços necessários à formação dos profissionais do magistério." (Brasil, 2015:4)

Na visão de Manfredo (2008), a indissociabilidade entre ensino, pesquisa e extensão consiste em uma importante ênfase da ação universitária ao permitir o exercício da responsabilidade social da Universidade perante a comunidade em que está inserida, por meio da proposição de projetos de extensão integrados ao ensino e à pesquisa que propiciam a produção de novos saberes e o compartilhamento entre os conhecimentos presentes em seus diferentes contextos, de forma a contribuir para o desenvolvimento tanto da Universidade quanto da comunidade.

Esse enfoque está em consonância com o exposto no Plano Nacional de Extensão Universitária (Brasil, 2001), que indica que

"a Extensão é uma via de mão dupla, com trânsito assegurado à comunidade acadêmica, que encontrará, na sociedade, a oportunidade de elaboração da práxis de um conhecimento acadêmico" (Brasil, 2001:5).

Tal legislação indica ainda que, ao retornar para a Universidade, docentes e discentes devem submeter o aprendizado obtido na prática a uma reflexão teórica:

"Esse fluxo, que estabelece a troca de saberes sistematizados, acadêmicos e popular, terá como consequência: a produção do conhecimento resultante do confronto com a realidade brasileira e regional; a democratização do conhecimento acadêmico e a participação efetiva da comunidade na atuação da Universidade." (Brasil, 2001:5)

Nessa perspectiva, concordamos com Siple, Mandler, Comiotto e Santos (2015) quando afirmam que os cursos de licenciatura devem desenvolver projetos que incentivem a interlocução entre as comunidades acadêmica e escolar visando ao enriquecimento de ambas. Especificamente em relação à formação inicial do futuro professor de matemática, Siple e outros (2015) aconselham a realização de ações extensionistas que proporcionem ao futuro professor "vivenciar, confrontar e recriar algumas metodologias e teorias adquiridas ao longo da Licenciatura e que serão fundamentais para o seu desenvolvimento profissional" (Siple e outros, 2015:2). Nesse sentido, apresentamos na próxima seção a vivência com a realidade escolar proporcionada pelo desenvolvimento da ação "Clube de Matemática na Escola" e suas contribuições junto ao processo formativo de uma acadêmica de Licenciatura em Matemática.

\section{As contribuições na formação inicial de um professor de Matemática advindas do desenvolvimento de um Clube de Matemática}

A acadêmica que participa como bolsista do projeto de Extensão "Clube de Matemática na Escola" (ação vinculada ao Programa "Ensino de Ciências e Matemática: abordagens interdisciplinares") é aluna do quinto período do curso de Licenciatura em Matemática da UDESC. Na atual etapa de sua graduação, a acadêmica está cursando a segunda disciplina referente aos Estágios Curriculares Supervisionados, que de acordo com a legislação brasileira (Brasil, 2003), devem iniciar a partir da segunda metade do curso e totalizar uma carga horária de estágio correspondente a 400 horas. Na disciplina Estágio Curricular Supervisionado I, os acadêmicos têm o seu primeiro contato formal com as escolas de Ensino Básico, com os respectivos estudos centrados na análise da fundamentação pedagógica e no conhecimento e funcionamento das escolas públicas e privadas de Ensino Fundamental e Médio. Na disciplina de Estágio Curricular Supervisionado II, o objeto de estudo centra-se na análise e organização dos programas curriculares das disciplinas de Matemática oferecidas nas escolas básicas, mediante reflexão sobre documentos oficiais. Apenas nas disciplinas de Estágio Curricular Supervisionado III e IV (a ser cursados nos dois últimos períodos) que os acadêmicos passam a ministrar aulas de matemática na escola básica, por meio dos estágios chamados de regência no Ensino Fundamental e Ensino Médio, respectivamente.

Dessa forma, a acadêmica, cujo processo formativo está em discussão nesse texto, antes de iniciar suas atividades como bolsista do projeto de extensão, ainda não possuía nenhuma experiência formal de regência de conteúdos matemáticos junto a alunos do ensino básico.

A acadêmica iniciou suas atividades no Clube de Matemática em março de 2015 e desde então é responsável, juntamente com a equipe de professores orientadores, por idealizar, planejar, executar e relatar as experiências desenvolvidas junto a um público constituído por cerca de 30 (trinta) alunos do ensino fundamental de uma escola pública. A sua principal responsabilidade consiste em explorar, por meio de encontros semanais realizados no contra turno letivo, conteúdos curriculares de matemática do nível básico, com ênfase na utilização da metodologia de Jogos para o Ensino de Matemática, com o propósito de oferecer ao público participante o aprendizado de conhecimentos matemáticos mediante formas mais atrativas de ensino, que evidenciem os aspectos lúdicos e lancem mão de recursos pedagógicos diferenciados.

Dentre os objetivos específicos, cujo alcance é esperado com a proposição e execução de tais atividades extensionistas, destacamos a valorização da utilização de jogos e demais artefatos didáticos para o ensino de Matemática; a promoção do estudo de Matemática e a ampliação do interesse, curiosidade e motivação do estudante do Ensino Básico pela matemática, buscando que 
esse assuma uma postura mais comprometida com o seu próprio aprendizado (Azevedo e outros, 2016:5).

Para atingir tais objetivos, a acadêmica desenvolveu diversas atividades com o público alvo durante todo o ano letivo de 2015 e até o presente momento de 2016. As principais atividades aplicadas em 2015 podem ser consultadas em Azevedo e outros (2016), já as atividades em desenvolvimento em 2016 passaram a ser focadas na construção e adaptação de jogos tradicionais brasileiros visando ao ensino de matemática, sendo que este trabalho faz parte de uma pesquisa de mestrado profissional em Ensino de Ciências, Matemática e Tecnologias, cuja autora passou a integrar a equipe do Clube em setembro de 2015. Nesse contexto, acreditamos que as atividades em desenvolvimento vinculam a extensão com o ensino, ao proporcionar à acadêmica o contato direto com o ambiente escolar, sua futura área de atuação profissional, o qual the permite colocar em prática algumas das metodologias para o ensino de matemática, estudadas na graduação, e também se vinculam com a pesquisa, ao aliar o planejamento e execução das atividades extensionistas com os resultados parciais de uma pesquisa em andamento, permitindo aperfeiçoar tanto as técnicas de ensino utilizadas quanto o material didático em elaboração no mestrado profissional, permitindo que o campo da extensão sirva também como ambiente para testagem e avaliação dos produtos educacionais concebidos na pós-graduação.

Nessa perspectiva, a bolsista do Clube de Matemática tem a oportunidade de vivenciar, em um só momento, uma experiência de ensino, como processo de formação profissional, de pesquisa, como investigação sobre os resultados dos métodos utilizados em sua prática enquanto docente e, principalmente, de extensão, na medida em que sua prática consiste em uma intervenção sobre um contexto social concreto.

Em relação às contribuições no campo do ensino, a participação no projeto permite à acadêmica desenvolver o seu aprendizado para a docência, visto que a prática semanal junto aos alunos do Clube de Matemática lhe exige a realização do planejamento das atividades que serão abordadas, a definição de objetivos específicos para cada atividade, a escolha da melhor abordagem ou metodologia para que os resultados sejam alcançados, a avaliação dos alunos no desenvolvimento das atividades, tudo isso aliado a um domínio do conteúdo específico e a uma transposição didática desses conteúdos para que haja a compreensão dos alunos.

Além de todos esses pontos, a professora em formação também exercita outros conhecimentos exigidos dos professores, como o conhecimento pedagógico geral, o gerenciamento e organização da sala de aula, bem como o conhecimento sobre os alunos e as particularidades sobre como se processa o aprendizado desses alunos, exigindo muitas vezes que um determinado conceito seja explorado de diferentes modos, exigindo da professora em formação habilidades de comunicação e de interação social com os alunos. Ainda, com a inserção da professora em formação no ambiente escolar formal, esta também recebe contribuições advindas do contato com os demais professores de Matemática da escola, visto que esses podem colaborar no projeto, indicando quais conteúdos os alunos possuem maiores dificuldades e que poderiam ser tratados de uma forma diferenciada no Clube de Matemática. Dessa forma, o projeto permite à licencianda um contato com o corpo docente e com os gestores da própria escola, em especial com a coordenadora pedagógica, que além de fornecer todo o aparato prático para a realização do Clube, também acompanha as atividades desenvolvidas com um olhar voltado às necessidades da própria escola.

Nesse enfoque, acreditamos que o desenvolvimento do Clube de Matemática pode ser visto como uma ação, mesmo que isolada, que se preocupa em contribuir com a diminuição do complexo problema posto por Pereira (2000), referente à "dicotomia existente entre a formação teórica e prática" que é oferecida nos cursos de licenciatura brasileiros e que se reflete na "desvinculação entre os conhecimentos específicos e pedagógicos dos conteúdos", bem como ajuda a diminuir o "distanciamento entre a formação acadêmica e as questões colocadas pela prática docente na Escola" (Pereira, 2000:57).

Quanto às contribuições no campo da pesquisa, acreditamos que o trabalho colaborativo desenvolvido entre a bolsista do projeto de extensão e a mestranda é extremamente salutar para ambas, visto que as atividades desenvolvidas são otimizadas de forma com que o Clube de Matemática também consista num campo de experimentação dos produtos educacionais desenvolvidos no âmbito da pós-graduação, ao mesmo tempo em que permite à licencianda desenvolver suas habilidades de professora pesquisadora, interagindo com os estudantes do ciclo básico de forma com que estes venham a desenvolver um aprendizado próprio, pautado nas suas próprias experiências na manipulação e confecção dos jogos e demais artefatos didáticos abordados no Clube de Matemática.

Por fim, as contribuições no campo da extensão são os mais visíveis, visto que o projeto permite com que a futura professora atinja diretamente um público alvo composto por cerca de 30 alunos (quantitativo equivalente a uma turma de ensino básico brasileiro), de forma a proporcionar a melhoria do aprendizado matemático desses alunos, a partir de metodologias que visam a considerar a matemática mais atrativa para esses estudantes, de forma com que esses passem a se dedicar mais ao estudo da matemática e vindo a proporcionar, em longo prazo, uma melhoria da qualidade da educação básica oferecida pela escola pública, que futuramente poderá ser medida pelo desempenho da escola nos instrumentos oficiais de avaliação da educação brasileira. 


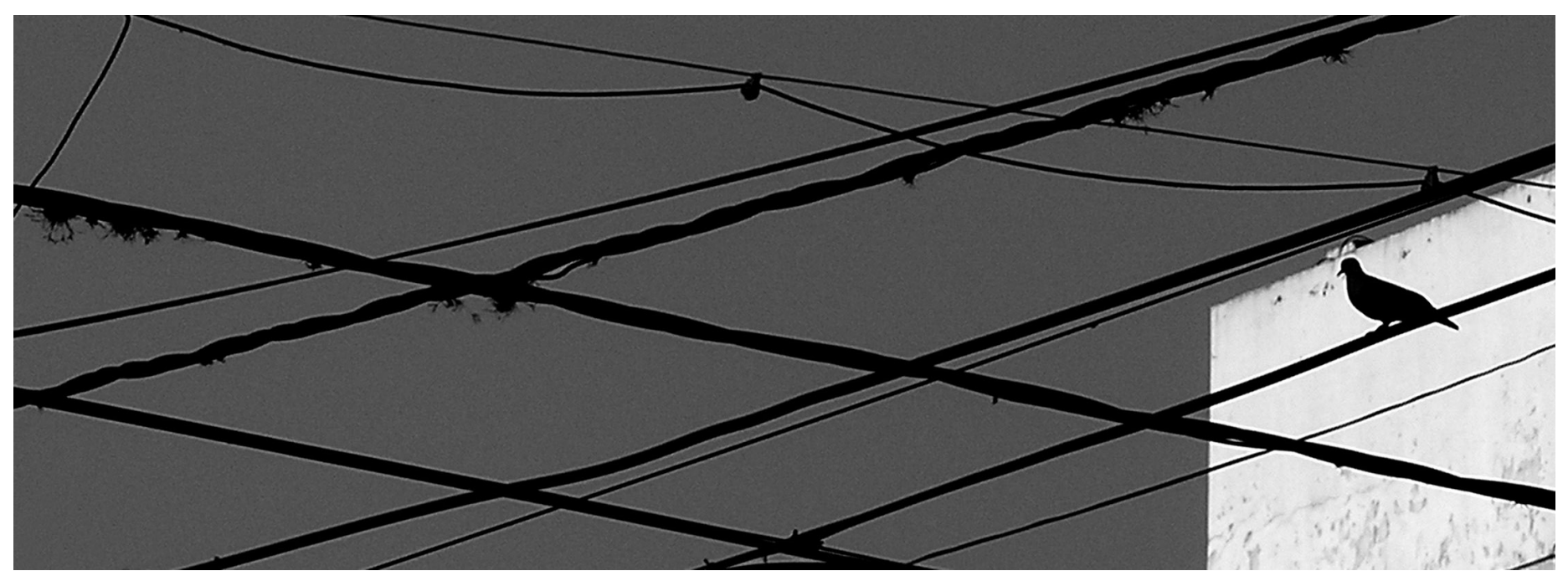

(c) Laura Hormaeche

\section{Conclusão e considerações finais}

Acreditamos que as ações do projeto de extensão Clube de Matemática na Escola, inserido no programa de extensão "Ensino de Ciências e Matemática: abordagens interdisciplinares" possibilitam ao futuro professor vivenciar a rotina da escola, com todos os seus fatores que influenciam no aprendizado dos alunos, permitindo a construção de conhecimentos bilaterais, que impactam tanto na formação da futura professora, que ao ter contato com o que ocorre no ambiente escolar, enfrentando as dificuldades e desafios presentes no processo educacional da escola básica, sofre um processo de enriquecimento em sua formação profissional, bem como na formação matemática dos alunos do ensino fundamental, público diretamente atingido com as atividades extensionistas que, por meio delas, permitem ampliar ou consolidar seus conhecimentos matemáticos escolares. Também destacamos que a realização de projetos e programas de extensão com esse enfoque viabiliza a aproximação da Universidade com o seu entorno social, permitindo uma integração humana e o compartilhamento de conhecimentos técnicos e metodológicos produzidos na academia e a socialização dos saberes típicos da escola que tanto enriquecem os processos de formação de novos professores quanto agregam valores profissionais às atuações dos próprios docentes universitários, responsáveis pela idealização de tais projetos.

Nessa perspectiva, esperamos ter evidenciado nesse texto as principais contribuições que um projeto de extensão pode proporcionar à formação inicial do futuro professor de matemática, ressaltando que tais iniciativas conferem um panorama positivo quanto à função social assumida pela Universidade, a partir de ações que considerem a extensão, a pesquisa e o ensino como elementos indissociáveis e integrados com a formação profissional.

\section{Referências bibliográficas}

Azevedo, E. B.; Moro, G.; Viana, J. B.; Mandler, M. L.; Munhoz, R. H.; Dunzer, S. (2016). No prelo. "Clube de Matemática: uma parceria entre Escola e Universidade propiciada por um projeto de extensão". In XII Encontro Nacional de Educação Matemática, São Paulo, Brasil: Anais do XII ENEM.

Brasil (2001). Plano Nacional de Extensão Universitária. Edição Atualizada. Fórum de Pró-Reitores de Extensão das Universidades Públicas Brasileiras e Secretaria do Ensino Superior (SESu) do Ministério da Educação e Cultura (MEC). Brasil. Brasil (2003). Ministério da Educação. Conselho Nacional de Educação. Resolução no 3, de 18 de fevereiro de 2003 - CNE/CES. Estabelece as Diretrizes Curriculares para os Cursos de Matemática. Recuperado de: portal.mec.gov.br/ cne/arquivos/pdf/ces032003.pdf (19/06/2016).

Brasil (2015). Conselho Nacional de Educação. Define as Diretrizes Curriculares Nacionais para a formação inicial em nível superior (cursos de licenciatura, cursos de formação pedagógica para graduados e cursos de segunda licenciatura) e para a formação continuada. Resolução CNE/CP n. 02/2015, de $1^{\circ}$ de julho de 2015. Brasília, Diário Oficial [da] República Federativa do Brasil, seção 1, (124), 8-12, 02 de julho. Recuperado de: portal.mec.gov.br/index.php?option=com_docman\&view=download\&alias=17719-res-cne-cp-002-03072015\&category_slug=julho-2015-pdf\&ltemid=30192 (10/06/2016).

Manfredo, E. C. G. (2008). Ensino-Pesquisa-Extensão: uma experiência no curso de Licenciatura em Matemática da UFPA em Jacundá. Revista Udesc em Ação, 2, 1-13.

Pereira, J.E.D. (2000). A formação de professores: pesquisas, representações e poder. Belo Horizonte, Brasil: Autêntica.

Siple, I. Z.; Mandler, M. L.; Comiotto, T.; Santos, L. M. (2015). Playground da Matemática: uma prática de extensão para a formação inicial de professores que ensinam matemática. En Conferência Internacional do Espaço Matemático em Língua Portuguesa CIEMeLP 2015. Coimbra, Portugal. Anais do CIEMeLP. 